\title{
Preparation and evaluation of antimicrobial activity of nanosystems for the control of oral pathogens Streptococcus mutans and Candida albicans
}

\author{
This article was published in the following Dove Press journal: \\ International Journal of Nanomedicine \\ 25 October 2011 \\ Number of times this article has been viewed
}

\section{Carolina Gonçalves Pupe' \\ Michele Villardi' \\ Carlos Rangel Rodrigues' \\ Helvécio Vinícius Antunes \\ Rocha $^{2}$ \\ Lucianne Cople Maia ${ }^{3}$ \\ Valeria Pereira de Sousa' \\ Lucio Mendes Cabral' \\ 'Depto de Medicamentos, Faculdade de Farmácia, UFRJ, Rio de Janeiro, ${ }^{2}$ Farmanguinhos/FIOCRUZ, Rio de Janeiro, ${ }^{3}$ Faculdade de Odontologia, UFRJ, Rio de Janeiro, Brazil}

\begin{abstract}
Background: Diseases that affect the buccal cavity are a public health concern nowadays. Chlorhexidine and nystatin are the most commonly used drugs for the control of buccal affections. In the search for more effective antimicrobials, nanotechnology can be successfully used to improve the physical chemical properties of drugs whilst avoiding the undesirable side effects associated with its use. Herein described are studies using nystatin and chlorhexidine with sodium montmorillonite (MMTNa), and chlorhexidine with $\beta$-cyclodextrin and two derivatives methyl- $\beta$-cyclodextrin and hydroxypropyl- $\beta$-cyclodextrin in the development of antimicrobial nanosystems.
\end{abstract}

Methods: The nanosystems were prepared by kneading and solubilization followed by freezedrying technique. The nanosystems were characterized by X-ray powder diffraction (XRPD), differential scanning calorimetry (DSC), and Fourier transform infrared spectroscopy (FTIR). Nanosystem antimicrobial activity against Streptococcus mutans and Candida albicans strains was evaluated with inhibition halo analysis.

Results: The nanocarriers MMTNa and cyclodextrins showed good yields. XRPD, FTIR, and DSC analysis confirmed the proposed nanosystems formation and the suitability of the production methods. The nanosystems that showed best antimicrobial effect were chlorhexidine gluconate (CHX) and cyclodextrin inclusion complexes and CHX:MMTNa 60\% cation exchange capacity -24 hours.

Conclusion: The nanosystem formulations present higher stability for all chlorhexidine inclusion complexes compared with pure chlorhexidine. The nystatin nanosystems have the potential to mask the bitter taste, justifying subsequent in-vivo studies. For these reasons, further studies are being carried out to evaluate their application in professional formulations. Keywords: sodium montmorillonite, chlorhexidine gluconate, buccal diseases, nanotechnology, cyclodextrins

\section{Introduction}

Diseases that affect the buccal cavity are considered a serious public health problem. Among the more prevalent are caries, periodontal disease, and the different types of oral candidiasis. Periodontal diseases and dental caries are usually caused by the presence of biofilm as a result of ineffective mechanical oral hygiene practices. For this reason, chemical agents are important to reduce gingivitis, periodontal disease, and dental caries. ${ }^{1}$ Candida albicans has already been isolated from the dental biofilm, caries, and the periodontal pockets, which together with Streptococcus mutans has more severe consequences. ${ }^{2}$ There are also several clinical issues associated
Correspondence: Valeria Pereira de Sousa Departamento de Medicamentos, Faculdade de Farmácia, UFRJ, Prédio do CCS, Bloco K, 2o andar, Sala I5, llha do Fundão, 2194|-590, Rio de Janeiro, Brazil Emailvaleria@pharma.ufrj.br 
with $C$. albicans which represent serious problems for treatment and prophylaxis. ${ }^{3}$ Therefore, the development of more effective therapies to treat these diseases is one of the major public dental health challenges. Chlorhexidine gluconate $(\mathrm{CHX})$ is an antiseptic agent widely used to inhibit the formation of gingivitis and periodontitis. ${ }^{4}$ This cationic biguanidine interacts with the bacterial anionic surface and alters the integrity of the bacterial cell membrane leading to cytoplasm precipitation. ${ }^{5}$ However, besides the usual stability problems, this drug presents frequent side effects including taste perception alteration and an increase in tooth discoloration. ${ }^{6,7}$ For these reasons, several cyclodextrin (CD) inclusion complexes have been developed to increase stability and improve antimicrobial activity. ${ }^{4,8}$ The synergic association of CHX and nystatin (NYS) is a good option for the simultaneous control of $C$. albicans and $S$. mutans. Like CHX, NYS has an unpleasant flavor that leads to nausea during oral application, limiting its use and reducing patient compliance despite its undoubted effectiveness in the control of candidiasis and other buccal cavity disorders. ${ }^{9}$ The formulation of nanostructured NYS and CHX could overcome the low solubility and stability problems of these drugs, producing a controlled release system with new improved antimicrobial activity. Previous reports have shown that a NYS and CHX $\beta$-cyclodextrin ( $\beta C D)$ inclusion can improve stability and solubility. ${ }^{4,10}$ However, better results can be obtained using nanocarriers with sustained release properties, such as sodium montmorillonite (MMTNa), the main constituent of bentonite $(60 \%)$. This nanocarrier may present some synergistic effect due to the capability of these materials to adsorb and fix bacteria and fungi, immobilizing their toxins, ${ }^{11}$ and also presents parallel lamellae with internal anionic surfaces and interlamellar cations for equilibrium and charge stabilization. Therefore, inclusion processes can occur with several different cations or small molecules, leading to substance encapsulation in the interlamellar space, increasing system tortuosity and water uptake. ${ }^{12}$ The use of MMTNa for acetate chlorhexidine inclusion has been previously reported, ${ }^{11}$ as has the use of $\beta C D$ for CHX and NYS encapsulation. ${ }^{4,10}$ However, the use of water-soluble methyl$\beta$-cyclodextrin (M $\beta C D)$ and hydroxypropyl- $\beta$-cyclodextrin (HP $\beta C D$ ) for CHX, and MMTNa for both drugs, are other possibilities to be studied in order to obtain stable formulations with tolerable taste. ${ }^{13}$

Although there are several techniques to obtain CD complexes, such as co-precipitation, paste complexation, extrusion, spray drying, and kneading, ${ }^{6,13-15}$ considering these drugs, most of the authors show only the application of solution technique. Taking into account the industrial applicability, it has become necessary to evaluate other options, as kneading, due the feasibility and low cost.

The aim of this study is the development of new nanostructured drug-delivery systems with industrial applicability containing classical drugs for control of buccal pathologies, NYS and CHX, in order to increase the drug stability and improve the taste and antimicrobial action. Prepared and tested were inclusion complexes of NYS and CHX with MMTNa, and CHX with $\beta C D$ and two derivatives, $M \beta C D$ and $\mathrm{HP} \beta C D$.

\section{Materials and methods Materials}

Ethanol 95\% (Merck, Darmstadt, Germany), MMTNa (Acros Chemical Co, Pittsburgh, PA), $\beta C D, M \beta C D$, and $\mathrm{HP} \beta C D$ (Wacker GmbH, Munich, Germany), NYS and chlorhexidine (Sigma, St Louis, MO) were pharmaceutical grade. Solutions were prepared with purified water obtained using a Milli- $Q^{\circledR}$ system (Millipore, Bedford, MA).

\section{Preparation of CD complexes}

The inclusion complexes CHX:CD were prepared by solubilization-freeze-drying and kneading at molar ratios of $1: 1,1: 2$, and $1: 3$, using $\beta C D, M \beta C D$, and $H P \beta C D$. Physical mixtures were prepared by mixing together CD and freezedried CHX in a mortar at the same molar ratios. Using the kneading method, $\mathrm{CD}$ and $\mathrm{CHX}$ were mixed in a mortar for 5 minutes. An ethanol:water $(70: 30 ; \mathrm{v} / \mathrm{v})$ solution was added, and the system mixed for 30 minutes to obtain a homogeneous paste. The paste was dried under reduced pressure and the granulometry adjusted using a 40 mesh sieve. Using the solution method, the appropriate proportions of CHX and CD were mixed in $20 \mathrm{~mL}$ of distilled water using a magnetic stirrer for 72 hours. The samples were frozen in liquid nitrogen and lyophilized. The particle size was also calibrated with a 40 mesh sieve. The inclusion yield was calculated by ultraviolet (UV) spectroscopy.

\section{Preparation of clay-based nanosystems}

NYS and CHX:MMTNa nanosystems were prepared with the solution method using different cation exchange capacity (CEC) values: $100 \%, 80 \%$, and $60 \%$ of the total MMTNa. The CEC value considered was 100 meqv of cation to $100 \mathrm{~g}$ of MMTNa. ${ }^{12}$ The inclusion reactions were performed in triplicate for different periods (1, 18, 24, and 48 hours), stirring at room temperature. The reaction mixtures were centrifuged at $4000 \mathrm{rpm}$ for 40 minutes, and the precipitates dried in a 
vacuum desiccator. The inclusion yield was calculated by UV spectroscopy.

\section{Characterization of nanosystems}

These nanosystems were characterized by X-ray powder diffraction (XRPD), Fourier transform infrared spectroscopy (FTIR), and differential scanning calorimetry (DSC). XRPD patterns of nanosystems, physical mixtures, and pure substances were recorded with a Rigaku Miniflex diffractometer BD11197 (Rigaku, Tokyo, Japan) using CuKo radiation with a current of $30 \mathrm{~mA}$, voltage of $40 \mathrm{kV}$, and a $2 \theta$ angle between $2^{\circ}$ and $20^{\circ}$. FTIR spectra were collected by an IR Prestige-21 Shimadzu A210045 (Shimadzu, Kyoto, Japan) spectrometer using $2 \% \mathrm{KBr}$ pellets and wavenumber between 4000 and $400 \mathrm{~cm}^{-1}$. DSC analyses were carried out with DSC 882e Mettler-Toledo equipment (Mettler-Toledo, Greifensee, Switzerland) using hermetically sealed aluminum pans under a nitrogen flow of $28 \mathrm{~mL} \cdot \mathrm{min}^{-1}$ and heating rate of $10^{\circ} \mathrm{C} \cdot \mathrm{min}^{-1}$.

\section{Evaluation of nanosystem antimicrobial activity}

The $S$. mutans (ATCC25175) and C. albicans (ATCC36901) strains were grown at $37^{\circ} \mathrm{C}$ for 24 hours in the presence of the two drugs being tested and the isolated carriers (CD and MMTNa), with simultaneous comparison with the $\mathrm{CHX}$ and MMTNa nanosystems and CHX $0.12 \%$ solution formulations. The inoculum containing $10^{6}$ cells $/ \mathrm{mL}$ was uniformly seeded on plates containing solid brain heart infusion broth. After drying the surface, $10 \mu \mathrm{L}$ of each sample was placed on the culture medium surface and incubated for 24 and 48 hours at $37^{\circ} \mathrm{C}$. The plates containing $S$. mutans were maintained in anaerobiosis for the incubation time. The inhibition effect was verified by the presence of inhibition zones around the area on the plate where the solution was deposited and sized for analysis and comparison.

\section{New $\mathrm{CHX}$ nanosystem formulations and stability test analysis}

Mouthwash formulations were developed with CHX $(0.120 \% \mathrm{w} / \mathrm{v})$ or with CD inclusion complexes. Watersoluble mint essence $(0.1 \% \mathrm{v} / \mathrm{v})$, ethanol $(0.050 \% \mathrm{v} / \mathrm{v})$, polysorbate $20(0.500 \% \mathrm{v} / \mathrm{v})$, sorbitol $(70 \% \mathrm{w} / \mathrm{w}$ aqueous solution, $15.0 \% \mathrm{v} / \mathrm{v})$, menthol $(0.010 \% \mathrm{w} / \mathrm{v})$, and water $(20 \%)$ were mixed until complete dissolution, and the volume was adjusted to $100 \%$ with water. The formulations were assayed by high efficiency liquid chromatography (HPLC) as described below. The HPLC system used was a LC-10 A/VP Shimadzu (Shimadzu, Kyoto, Japan) with a chromatography $\mathrm{C}_{18}$ column $(250 \mathrm{~mm} \times 4.6 \mathrm{~mm}, 5 \mu \mathrm{m}$ particle size), the mobile phase was methanol:water with triethylamine $0.4 \%(63: 37 ; \mathrm{v} / \mathrm{v})$ with a $0.8 \mathrm{~mL} \cdot \mathrm{min}^{-1}$ flow rate. The analysis was performed at room temperature, with a $20 \mu \mathrm{L}$ injection volume and monitored at a wavelength of $240 \mathrm{~nm}$. The running time was established at 15 minutes. ${ }^{6,16}$ The stability tests were performed based on International Conference on Harmonization guidelines ${ }^{17}$ with $\mathrm{CHX}$ alone and inclusion complex the CHX: $\beta \mathrm{C}, \mathrm{CHX}: \mathrm{M} \beta \mathrm{CD}$, and CHX:HP $\beta C D$. All the inclusion complexes were at a molar ratio of 1:1 and obtained by kneading. The formulations were conditioned in a Nova Ética (São Paulo, Brazil) climatic chamber set to a relative humidity of $45^{\circ} \mathrm{C} \pm 2{ }^{\circ} \mathrm{C}$ and $75 \% \pm 5 \%$. The CHX:HP $\beta C D$ inclusion complex preparation, formulation, and stability evaluation have not yet been described in the literature. The CHX assay was carried out according to the USP 34 . $^{6,16}$

\section{Statistical data analysis}

One-way analysis of variance and Wilcoxon matched pairs tests were used to analyze all data obtained in this study using StatSoft ${ }^{\circledR}$ STATISTICA (StatSoft Inc, Tulsa, OK) software.

\section{Results and discussion Preparation and characterization of $\mathrm{CHX}$ and $\mathrm{CD}$ inclusion complexes}

XRPD patterns of lyophilized CHX, $\beta C D$, and CHX: $\beta C D$ complex are presented in Figure 1. As expected, lyophilized CHX shows an amorphous pattern after water uptake, while $\beta C D$ shows a highly crystalline pattern. The XRPD patterns of the inclusion complexes show greater amorphous characteristics than pure $\beta C D$ and physical mixtures. This is evidence of inclusion, as this disorder phenomenon has already been described by Cortés and colleagues. ${ }^{18}$ These amorphous patterns are characterized by the disappearance and decrease of peak intensity - a decrease of $70 \%-80 \%$ with the kneading method and $80 \%-90 \%$ with the solution method. These amorphous patterns were observed at molar ratios of 1:1, 1:2, and 1:3.

The FTIR spectra of the $\beta C D$ inclusion complex (data not shown) showed the characteristic peaks of CHX at $1700-1500 \mathrm{~cm}^{-1}$, corresponding to aromatic ring $\mathrm{C}=\mathrm{C}$ stretching which is different from the $\beta C D$ peaks. The spectra of both the physical mixture and the complex illustrated the typical peaks of each material of which the inclusion complex is composed, with the presence of significant frequency 


\section{A}

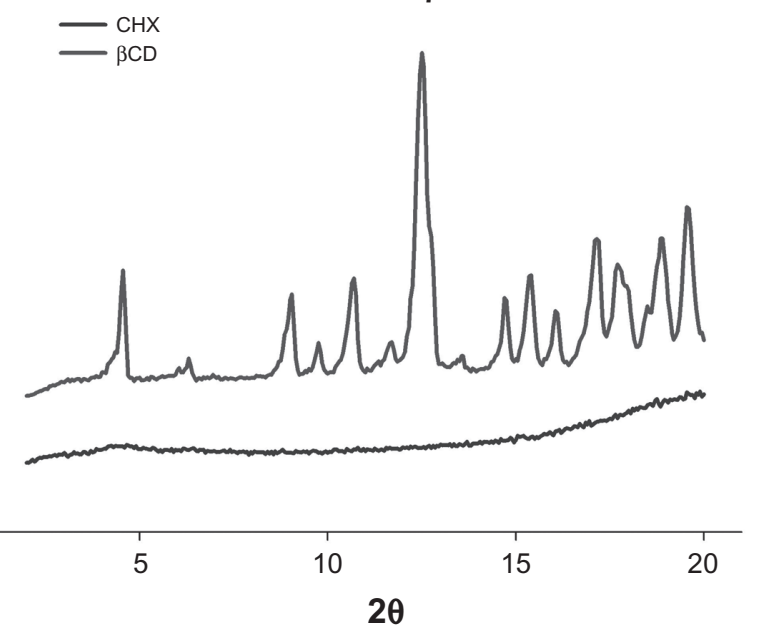

C

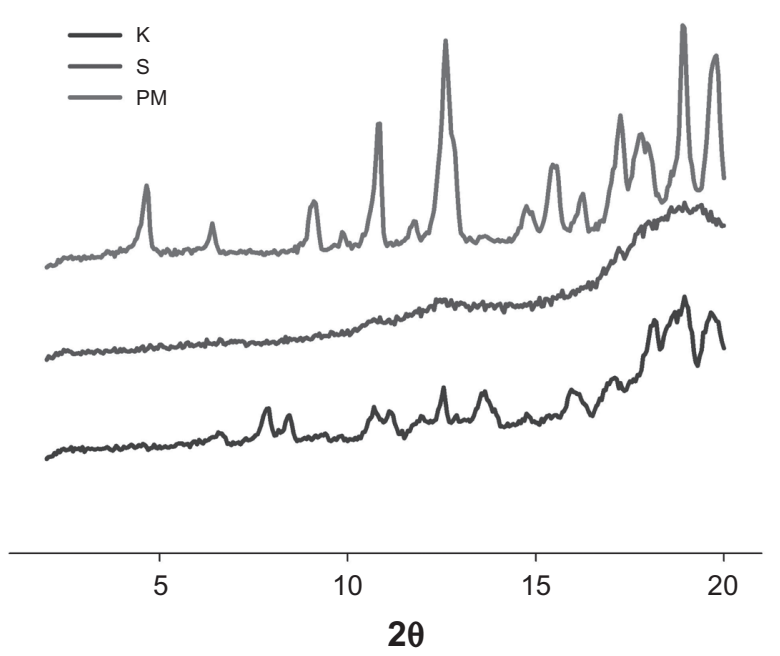

B

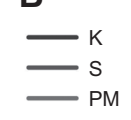

CHX: $\beta C D(1: 1)$
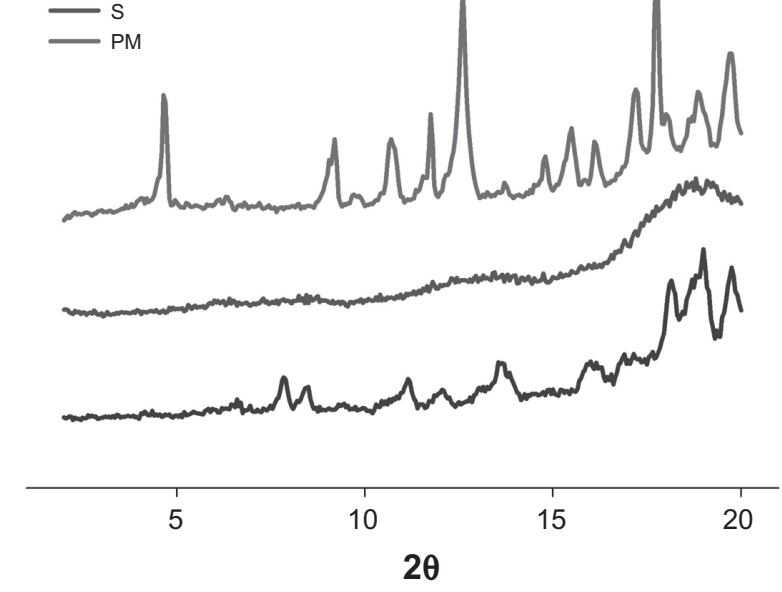

D

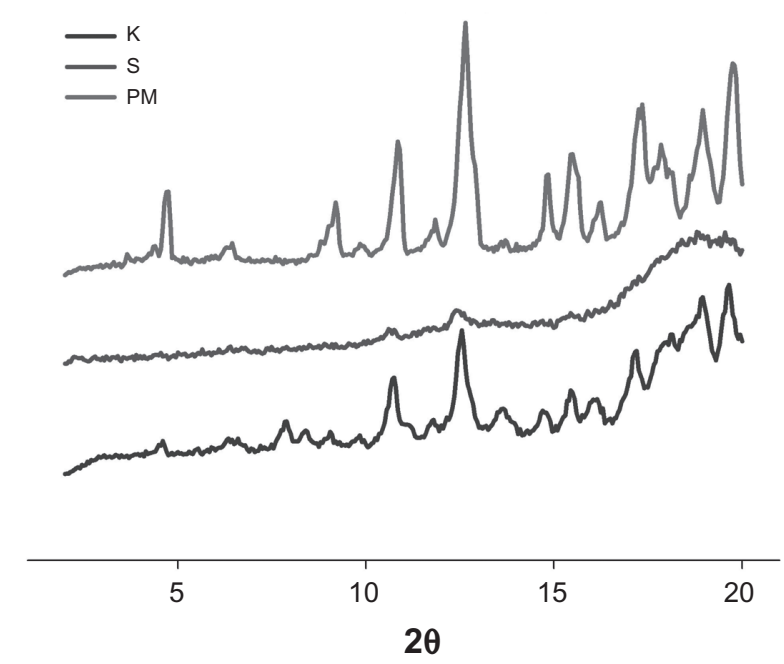

Figure I X-ray powder diffraction patterns of $(\mathbf{A}) \mathrm{CHX}$ and $\beta C D$, (B-D) physical mixture and inclusion complexes obtained by solubilization-freeze-drying and kneading at I:I (B), I:2 (C), and I:3 (D) molar ratios.

Abbreviations: $\beta C D$, $\beta$-cyclodextrin; $\mathrm{CHX}$, chlorhexidine; $\mathrm{K}$, kneading; PM, physical mixture; S, solubilization-freeze-drying.

shifts. These results demonstrate the efficacy of the inclusion process with a CHX presence. ${ }^{18}$

As observed for $\beta C D, M \beta C D$ presents a crystalline pattern (XRPD) and inclusion is evidenced by sample amorphization. The peak decrease was observed in samples prepared by both methods and at all molar ratios: 1:1, 1:2, and 1:3. In this case, it was not possible to differentiate between the two inclusion methods by XRPD. This lack of crystallinity indicates inclusion complex formation as shown by Figueiras and colleagues. ${ }^{19}$ The characteristic peaks of both CHX and $\mathrm{M} \beta \mathrm{CD}$ can be seen in the FTIR spectra of the inclusion complexes with significant shifts, confirming the presence of CHX in the inclusion processes.
The characteristic peaks of HP $\beta C D$ are at $2 \theta$ angles of $11.4^{\circ}$ and $19.3^{\circ}$. A $60 \%$ peak reduction can be observed in the XRPD pattern of the complex produced by kneading at a 1:1 molar ratio. The samples produced by the solution method did not show significant peak reduction, meaning that the method employed is determinative to this complex formation. Wang and colleagues observed the same characteristics producing trans-ferulic acid complexes. ${ }^{20}$ The characteristic peaks of both CHX and HP $\beta C D$ were demonstrated by the FTIR spectra of the inclusion complexes with significant shifts, confirming the effect of the presence of CHX in the production processes.

Thermal analysis, which is based on the comparison of the thermal behavior of single components, their physical 
mixture, and inclusion complexes, is the usual technique for qualitative investigation of $\mathrm{CD}$ inclusion complex formation. ${ }^{21}$ DSC curves for the pure substances and inclusion compounds are shown in Figure 2. The DSC curve of CHX shows stability from $25^{\circ} \mathrm{C}$ to $174^{\circ} \mathrm{C}$, after which, a sequence of thermal decomposition events were observed. DSC curves of inclusion compounds show that the $\mathrm{CHX}$ degradation peak temperature was higher for all inclusion complexes obtained with $\beta C D$ and its synthetic derivatives (M $\beta C D$ and $H P \beta C D)$. This evidences a new supramolecular compound formation characteristic of inclusion complexes with improved stability. The disappearance or flattening of the drug melting point peak are considered conclusive evidence of inclusion compound formation. ${ }^{21}$ Yallapu and colleagues have observed these same patterns for curcumin complexation, where the melting endothermic peak of the drug completely disappeared in the DSC curves. ${ }^{22}$

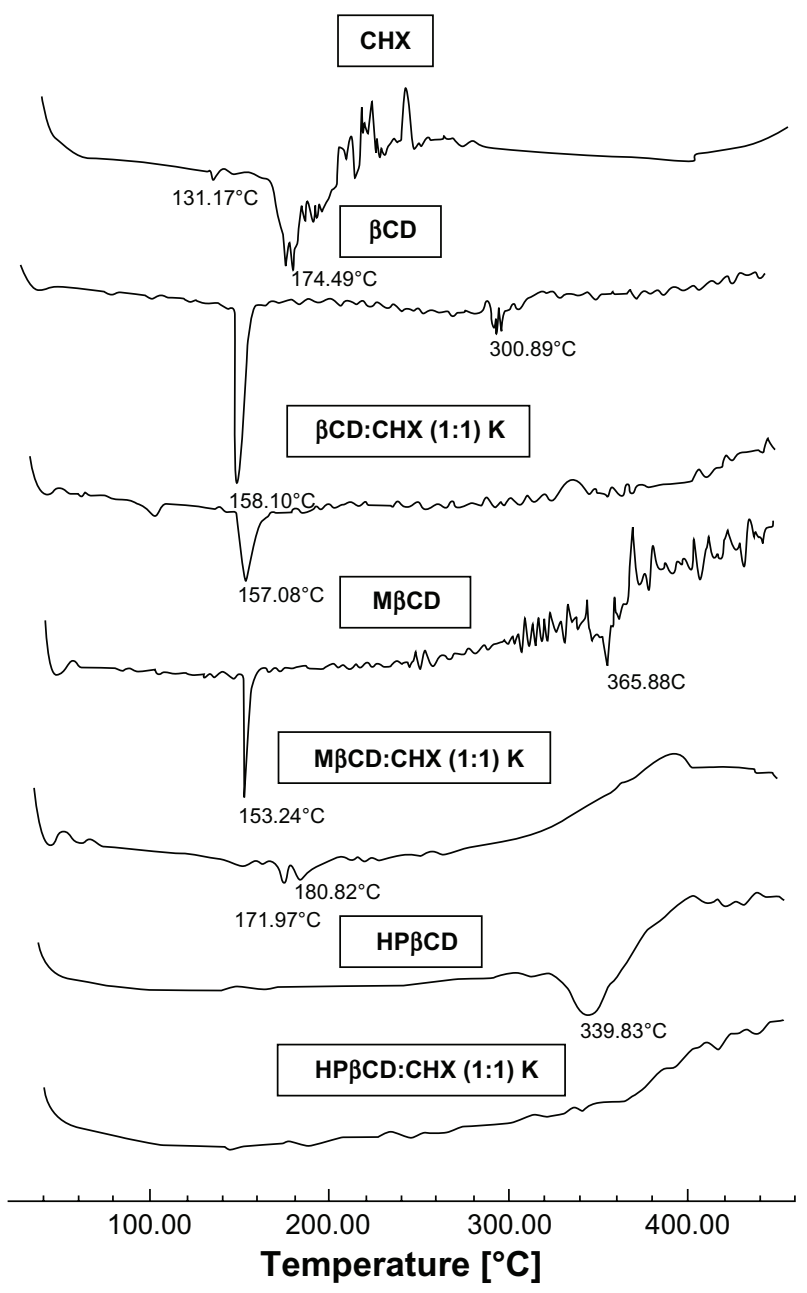

Figure 2 Differential scanning calorimetry curves of $C H X, \beta C D, M \beta C D, H P \beta C D$, and inclusion complexes obtained by kneading at a I:I molar ratio.

Abbreviations: $\beta C D, \beta$-cyclodextrin; $C H X$, chlorhexidine; $H P \beta C D$, hydroxypropyl$\beta$-cyclodextrin; $K$, kneading; $M \beta C D$, methyl- $\beta$-cyclodextrin; Temp, temperature.
In all $\mathrm{CD}$ derivatives studied, the kneading method was chosen to prepare inclusion complexes of $\mathrm{CHX}, \beta \mathrm{CD}, \mathrm{M} \beta \mathrm{CD}$, and $\mathrm{HP} \beta C D$ at a 1:1 molar ratio, due its low cost and industrial applicability.

\section{Preparation and characterization of clay-based nanosystems}

MMTNa was used as a nanocarrier due to its sustained release properties and synergistic antimicrobial activity. The nanosystems produced were characterized by XRPD, DSC, and FTIR. A decrease in the $2 \theta$ value observed in the XRPD analysis is an indicative factor of the inclusion process since a reduction in this angle is associated with an increase in basal spacing, which is related to drug inclusion. ${ }^{23}$ The chlorhexidine nanosystem obtained showed a $2 \theta$ value decrease, described in Table 1, when compared with pure MMTNa, indicating the success of the inclusion process. However, there is no significant difference between all the proposed conditions presented in Table $1(P>0.05)$. CHX molecule rearrangement should also be considered since, like an alkyl ammonium chain, CHX may have a particular conformation that expands basal spacing in low concentration between lamellae. Absorption of $\mathrm{CHX}$ can occur when a high concentration is used for inclusion. In order to avoid this, a $60 \%$ CEC was used (24 hours). Under these conditions, the inclusion complex presented an average lamellar spacing of $16.8 \pm 1.3 \AA$ and an inclusion yield of $70.0 \% \pm 0.02 \%$. These results corroborate those observed by Meng and colleagues $^{11}$ and Yang and colleagues, ${ }^{24}$ who reported an interlamellar space increase from 15.1 to $19.4 \AA$ and 14.5 to

Table I Inclusion process results obtained with MMTNa and $\mathrm{CHX}$

\begin{tabular}{|c|c|c|c|c|c|}
\hline \multicolumn{3}{|l|}{$\begin{array}{l}\text { Intercalation } \\
\text { conditions }\end{array}$} & $2 \theta\left({ }^{\circ}\right)$ & $\begin{array}{l}\text { Basal } \\
\text { spacing (A) }\end{array}$ & $\begin{array}{l}\text { Indirect } \\
\text { yield (\%) }\end{array}$ \\
\hline \multicolumn{6}{|l|}{ MMTNa } \\
\hline MMTNa & & & 6.55 & $|3.8|$ & - \\
\hline \multicolumn{6}{|l|}{ CHX:MMTNa } \\
\hline \multirow[t]{4}{*}{ CHX:MMTNa $60 \%$} & $\mathrm{I} \mathrm{h}$ & $\mathrm{Cl}$ & 5.25 & 16.83 & 71 \\
\hline & $18 \mathrm{~h}$ & $\mathrm{C} 2$ & 5.40 & 16.37 & 7I \\
\hline & $24 \mathrm{~h}$ & $\mathrm{C} 3$ & 5.05 & 17.50 & 70 \\
\hline & $48 \mathrm{~h}$ & $\mathrm{C} 4$ & 5.20 & 16.99 & 79 \\
\hline \multirow[t]{4}{*}{ CHX:MMTNa $80 \%$} & $\mathrm{I} \mathrm{h}$ & $\mathrm{C} 5$ & 5.00 & 17.67 & 50 \\
\hline & $18 \mathrm{~h}$ & $\mathrm{C} 6$ & 5.05 & 17.50 & 58 \\
\hline & $24 \mathrm{~h}$ & $\mathrm{C7}$ & 5.10 & 17.33 & 61 \\
\hline & $48 \mathrm{~h}$ & $\mathrm{C} 8$ & 5.20 & 16.99 & 76 \\
\hline \multirow[t]{4}{*}{ CHX:MMTNa $100 \%$} & $\mathrm{Ih}$ & $\mathrm{C9}$ & 5.00 & 17.67 & 36 \\
\hline & $18 \mathrm{~h}$ & $\mathrm{ClO}$ & 5.00 & 17.67 & 45 \\
\hline & $24 \mathrm{~h}$ & $\mathrm{Cll}$ & 5.10 & 17.33 & 46 \\
\hline & $48 \mathrm{~h}$ & $\mathrm{C} 12$ & 4.95 & 17.85 & 50 \\
\hline
\end{tabular}

Abbreviations: $\mathrm{CHX}$, chlorhexidine; h, hour; MMTNa, sodium montmorillonite. 
16.6 A, respectively, for CHX acetate. These authors have observed that the CHX molecular volume is around $0.5 \mathrm{~nm}$, slightly less than the $0.69 \mathrm{~nm}$ calculated by subtracting the MMTNa monolayer size $(0.96 \mathrm{~nm})$ from the basal spacing measurement $(1.65 \mathrm{~nm})$. This larger molecular volume may be due to a different conformation assumed by $\mathrm{CHX}$ in MMTNa lamellae. ${ }^{11}$

DSC curves for the pure substances and nanosystems are shown in Figure 3. Nanosystem C3 shows an endothermic peak between $200^{\circ} \mathrm{C}$ and $220^{\circ} \mathrm{C}$, which may indicate the release of CHX from lamellar spacing. This result may be evidence that substances intercalated between clay lamellae can be observed through the calorimetric patterns of nanosystems at different temperatures. ${ }^{24}$

FTIR spectra of pure CHX, MMTNa, physical mixtures, and nanosystems present characteristic stretching bands due to water absorption at $3462 \mathrm{~cm}^{-1}, 3400 \mathrm{~cm}^{-1}$, and $3420 \mathrm{~cm}^{-1}$. The hydroxyl group from the Al-OH bond presents a stretching band at around $3620 \mathrm{~cm}^{-1}$. Vibration bands of silicate between montmorillonite lamellae are shown at $1114 \mathrm{~cm}^{-1}$ and $1047 \mathrm{~cm}^{-1}$ for the Si-OH bond. ${ }^{11,25}$ Regarding the spectra of CHX, this shows a shift of the stretching bands for the aromatic N-H and C-H bonds at $3396 \mathrm{~cm}^{-1}$ and $3226 \mathrm{~cm}^{-1}$ respectively. It is important to note that the spectra of the physical mixture, which simulates $\mathrm{C} 3$, showed differences when compared with the spectra of the inclusion process, indicating their contrasting profiles and confirming the inclusion process.

The NYS:MMTNa inclusion studies showed a $2 \theta$ value decrease in relation to pure MMTNa, which is evidence of nanosystem formation under all tested conditions (Table 2). However, the 24-hour inclusion period produced a larger basal spacing with all tested CEC. The nanosystem N3 (60\% CEC) was chosen for characterization due to the higher basal spacing compared with $100 \% \mathrm{CEC}$ and the economic aspect. This nanosystem presented an average lamellae spacing of $16.63 \pm 0.33 \AA$ (Figure 4) and an indirect inclusion yield of $54 \% \pm 0.01 \%$.

XRPD profiles for the pure substances and nanosystem N3 at different CEC values are shown in Figure 4. Nanosystem N3 shows a higher $2 \theta$ value when compared with MMTNa. This result is evidence of inclusion complex formation in the clay lamellae.

The calorimetric pattern of NYS derivatives are shown in Figure 5. The characteristic thermal event related to NYS, its melting point, occurs between $160^{\circ} \mathrm{C}$ and $180^{\circ} \mathrm{C}$, but this is not registered on the DSC curve of the NYS:MMTNa $60 \%$ CEC - 24-hour nanosystem. This pattern is similar to the

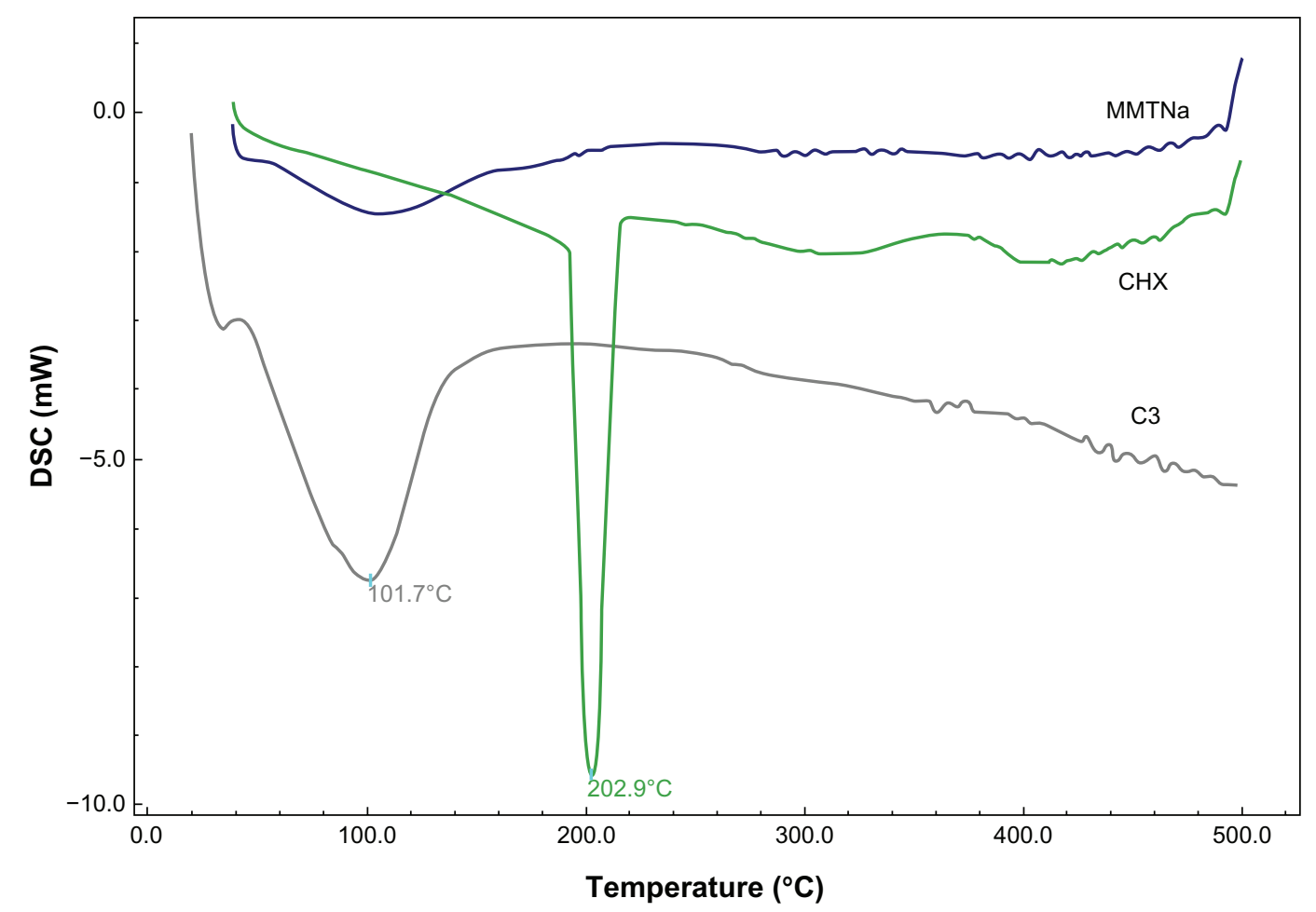

Figure 3 DSC curves of MMTNa, CHX, and nanosystems with $60 \%$ CEC - 24 hours (C3).

Abbreviations: CEC, cation exchange capacity; CHX, chlorhexidine; DSC, differential scanning calorimetry; MMTNa, sodium montmorillonite. 
Table 2 Inclusion process results obtained with MMTNa and NYS

\begin{tabular}{llllll}
\hline $\begin{array}{l}\text { Intercalation } \\
\text { conditions }\end{array}$ & & $\mathbf{2 \theta}\left(^{\circ}\right)$ & & $\begin{array}{l}\text { Basal } \\
\text { spacing (A) }\end{array}$ & $\begin{array}{l}\text { Indirect } \\
\text { yield (\%) }\end{array}$ \\
\hline NYS:MMTNa 60\% & I h & NI & 5.90 & 14.98 & 5 I \\
& I8 h & N2 & 5.65 & 15.64 & 52 \\
& $24 \mathrm{~h}$ & N3 & 5.20 & 16.99 & 54 \\
& 48 h & N4 & 5.95 & 14.85 & 46 \\
NYS:MMTNa 80\% & I h & N5 & 5.45 & 16.22 & 53 \\
& I8 h & N6 & 5.60 & 15.78 & 49 \\
& 24 h & N7 & 5.20 & 16.99 & 55 \\
& 48 h & N8 & 5.75 & 15.37 & 43 \\
NYS:MMTNa I00\% & I h & N9 & 5.40 & 16.37 & 47 \\
& I8 h & NI0 & 5.60 & 15.78 & 46 \\
& $24 \mathrm{~h}$ & NII & 5.55 & 15.92 & 5 I \\
& 48 h & NI2 & 6.00 & 14.73 & 44 \\
\hline
\end{tabular}

Abbreviations: h, hour; MMTNa, sodium montmorillonite; NYS, nystatin.

pure MMTNa with an endothermic peak at $100^{\circ} \mathrm{C}$ due to water loss. The absence of NYS endothermic melting point is evidence of inclusion, since the presence of the drug in the nanosystem was confirmed by FTIR analysis (data not shown).

\section{Evaluation of antimicrobial activity}

The inhibition halo technique has the greatest applicability in the evaluation of antimicrobial activity of biologically active montmorillonite-chlorhexidine nanocomposite..$^{24,26}$ Therefore, the inhibition halo technique was used to evaluate and compare the activity of the nanosystems and pure drugs and the possible synergy of the drugs with clays and $C D$. The samples tested were $C H X: \beta C D$,
CHX:M $\beta C D$, and CHX:HP $\beta C D$. These nanosystems were prepared by kneading, using $\mathrm{CHX}$ and $\mathrm{CDs}$ at a 1:1 molar ratio. The control solution was $0.12 \% \mathrm{CHX}$ aqueous solution $(\mathrm{w} / \mathrm{v})$. The inhibition halo diameters observed for $C$. albicans and $S$. mutans are shown in Table 3. All samples showed very similar activity and were quite similar to the $\mathrm{CHX}$ aqueous solution against Gram-positive bacteria and fungi. However, Cortés and colleagues ${ }^{18}$ have shown that a $\mathrm{CHX}$ : $\beta C D$ inclusion complex demonstrated modified antimicrobial activity when its minimum inhibitory concentration was measured, increasing its efficacy against pathogenic bacteria. These results were not observed in this work. Herein, contrary results were obtained with no statistical difference in the samples tested $(P=0.07653)$.

The halo diameters of the MMTNa nanosystems are represented in Table 4 and Figure 6. The MMTNa suspension did show any inhibition activity, which corroborates results shown by other authors. ${ }^{11,24,26,27}$ These authors not only tested sodium but also calcium montmorillonite. Thus, any synergic effect can be attributed to the absorptive properties of clay.

$\mathrm{CHX}$ aqueous solution $0.12 \%$ and the $\mathrm{C} 3$ derivative showed a large growth inhibition zone for both microorganisms. Halos for the CHX solution against $S$. mutans were between 26 and $27 \mathrm{~mm}$, while the C3 derivative presented halos of around 21-22 mm. Furthermore, halos against C. albicans of 18, 19, and $26 \mathrm{~mm}$ were observed using the CHX solution, and 11, 12, and $20 \mathrm{~mm}$ with the

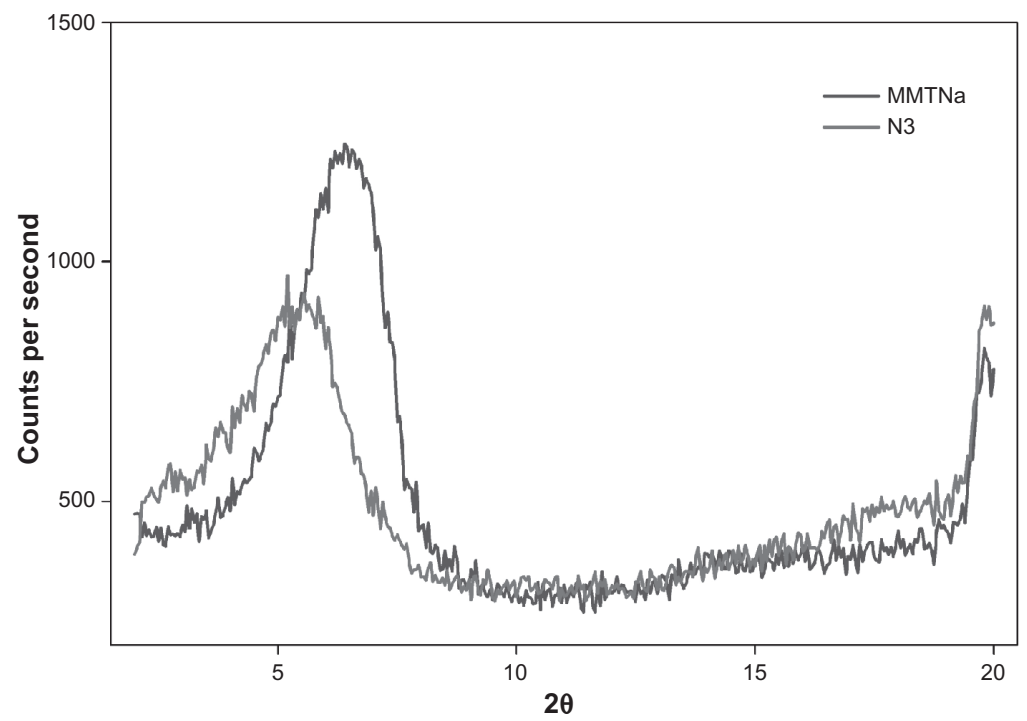

Figure 4 X-ray powder diffraction patterns of MMTNa and NYS-and-MMTNa nanosystems (NYS:MMTNa) with 60\% CEC - 24 hours (N3). Abbreviations: CEC, cation exchange capacity; MMTNa, sodium montmorillonite; NYS, nystatin. 


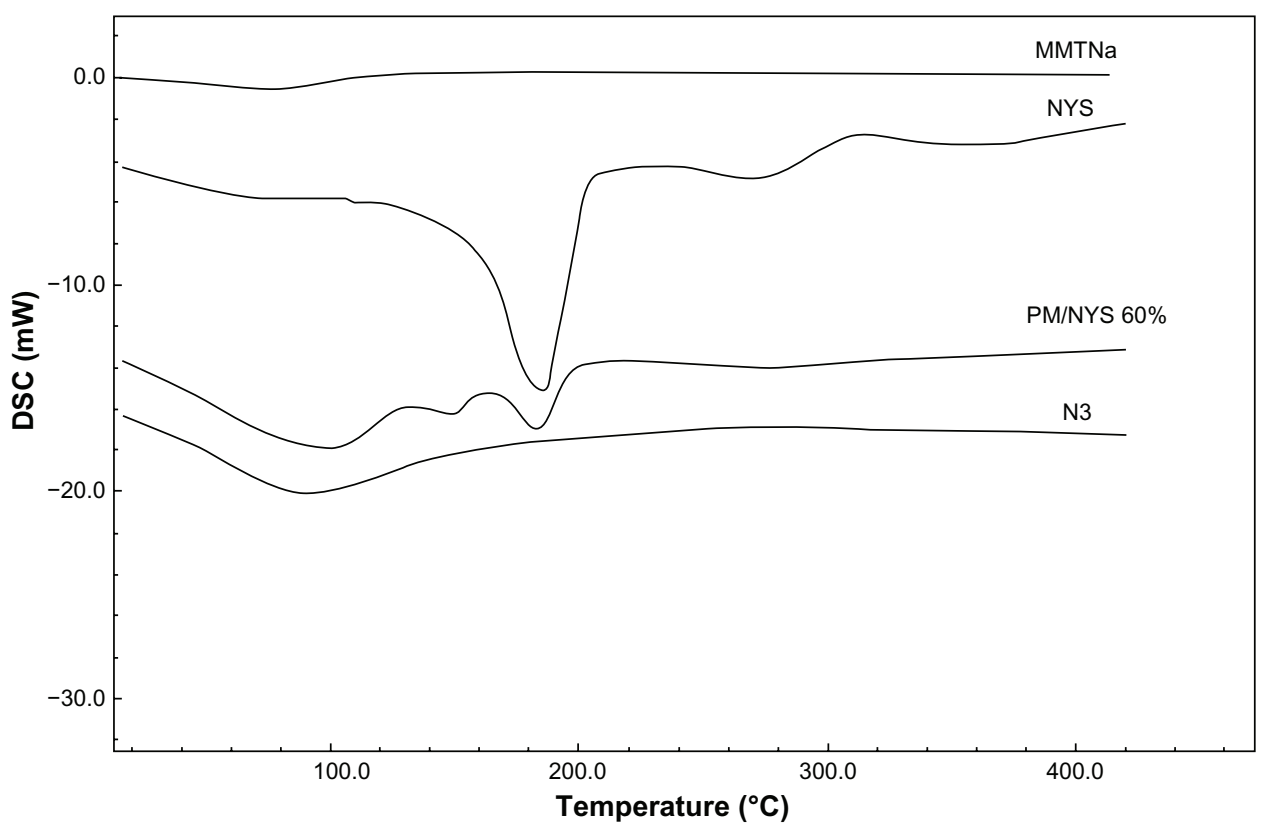

Figure 5 DSC curves of MMTNa, NYS, physical mixture of 60\% CEC (NYS:MMTNa PM), and NYS:MMTNa 60\% CEC - 24-hour nanosystem (N3).

Abbreviations: CEC, cation exchange capacity; DSC, differential scanning calorimetry; MMTNa, sodium montmorillonite; NYS, nystatin; PM, physical mixture; Temp, temperature.

C3 derivative. The smaller halo diameters presented by the C3 derivative were expected since it is an inclusion product with known prolonged release characteristics. ${ }^{24,27}$ Yang and colleague ${ }^{24}$ studied the antimicrobial activity of chlorhexidine acetate:MMTNa nanosystems and found that $\mathrm{CHX}$ was released slowly and the inhibition halo could be seen after 1 year. However, the results of this present study show that the CHX C3 derivative presented acceptable immediate release properties without total drug release, which is ideal for the treatment of oral diseases.

Pure NYS, an antifungal agent, did not show any inhibition activity against $S$. mutans, as expected, but presented halos ranging from 16, 19, and $27 \mathrm{~mm}$ against C. albicans strains (Table 4, Figure 6). These results are similar to those found by Carrillo-Muñoz and colleagues of $20 \mathrm{~mm} .{ }^{28}$ The NYS nanosystem was expected to show the same prolonged release profile as $\mathrm{C} 3$, but did not present any initial inhibition,

Table 3 Inhibition halo diameters of $\mathrm{CHX}$ (control) and inclusion complexes against Streptococcus mutans and Candida albicans

\begin{tabular}{lcccccc}
\hline \multicolumn{3}{c}{ S. mutans } & \multicolumn{5}{c}{ C. albicans } \\
\hline \multicolumn{3}{l}{ Inhibition halo diameters $(\mathbf{m m})$} \\
$\mathrm{CHX}: \beta C D$ & 17 & 17 & 17 & 15 & 15 & 15 \\
$\mathrm{CHX}: \mathrm{M} \beta C D$ & 18 & 18 & 18 & 16 & 16 & 16 \\
$\mathrm{CHX}: \mathrm{HP} \beta C D$ & 17 & 17 & 17 & 16 & 15 & 15 \\
$\mathrm{CHX}$ & 17 & 17 & 17 & 16 & 16 & 15 \\
\hline
\end{tabular}

Abbreviations: $\beta C D$, $\beta$-cyclodextrin; $C H X$, chlorhexidine; $H P \beta C D$, hydroxypropyl$\beta$-cyclodextrin; $M \beta C D$, methyl- $\beta$-cyclodextrin. indicating that the release is possibly slower than chlorhexidine due to lower NYS solubility in water and saliva. However, the large fluid volume in vivo could lead to a more effective release, justifying the use of this nanosystem in prolonged release tablets, which could be a therapeutic alternative to more complex pharmaceutical forms.

\section{Development of inclusion complexes in oral solutions and stability test}

Initially, the CHX stability in a mouthwash formulation was investigated because CHX has several incompatibilities with common excipients, such as some ions and organic compounds. These incompatibility reactions lead to the

Table 4 Inhibition halo diameters of pure substances and developed derivatives against Streptococcus mutans and Candida albicans strains using three different plating techniques

\begin{tabular}{|c|c|c|c|c|c|c|}
\hline & \multicolumn{3}{|c|}{ S. mutans } & \multicolumn{3}{|c|}{ C. albicans } \\
\hline & Plate I & Swab Ia & Swab $2^{b}$ & Plate I & Swab Ia & Swab $2^{b}$ \\
\hline \multicolumn{7}{|c|}{ Inhibition halo diameters ( $\mathrm{mm}$ ) } \\
\hline MMT & 0 & 0 & 0 & 0 & 0 & 0 \\
\hline $\mathrm{CHX}$ & 27 & 26 & 27 & 18 & 19 & 26 \\
\hline $\mathrm{C}^{\mathrm{c}}$ & 22 & 21 & 21 & 11 & 12 & 20 \\
\hline NYS & 0 & 0 & 0 & 16 & 19 & 27 \\
\hline$N 3^{d}$ & 0 & 0 & 0 & 0 & 0 & 0 \\
\hline
\end{tabular}



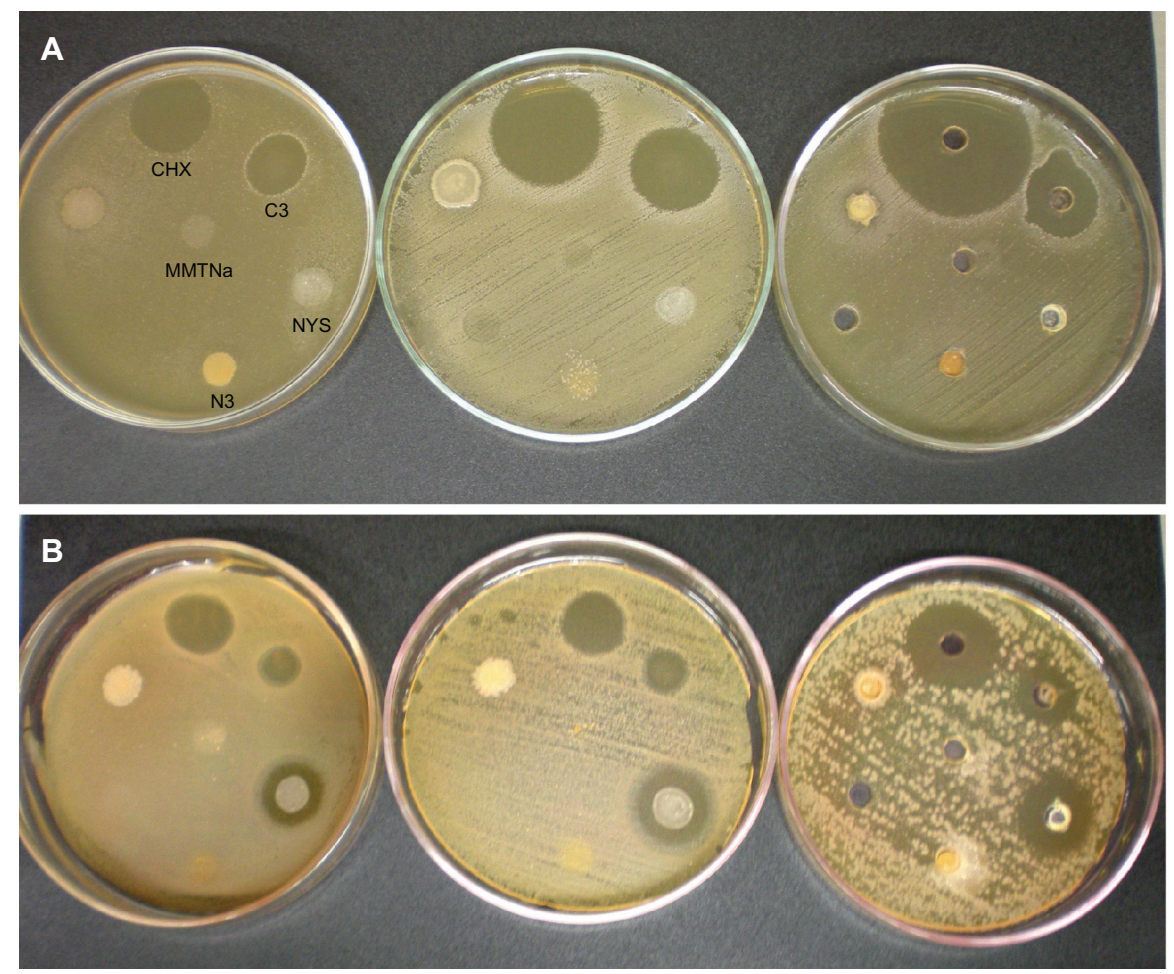

Figure 6 Inhibition halo analysis using (A) Streptococcus mutans $(\mathrm{n}=3)$ and $(\mathbf{B})$ Candida albicans strains $(\mathrm{n}=3)$ of $\mathrm{CHX}$ aqueous solution $0.12 \%$, CHX derivative $60 \%$ CEC 24 hours (C3), NYS, NYS derivative 60\% CEC - 24 hours (N3), and MMTNa.

Note: The inoculum in all Petri dishes followed the order displayed on the first dish.

Abbreviations: $\mathrm{CHX}$, chlorhexidine; MMTNa, sodium montmorillonite; NYS, nystatin.

formation of the degradation product $p$-chloroaniline and its subsequent precipitation. ${ }^{29,30}$ No precipitation or incompatibility was observed between CHX and formulation excipients 48 hours after formulation preparation with pure CHX. Mouthwash formulations were produced with pure

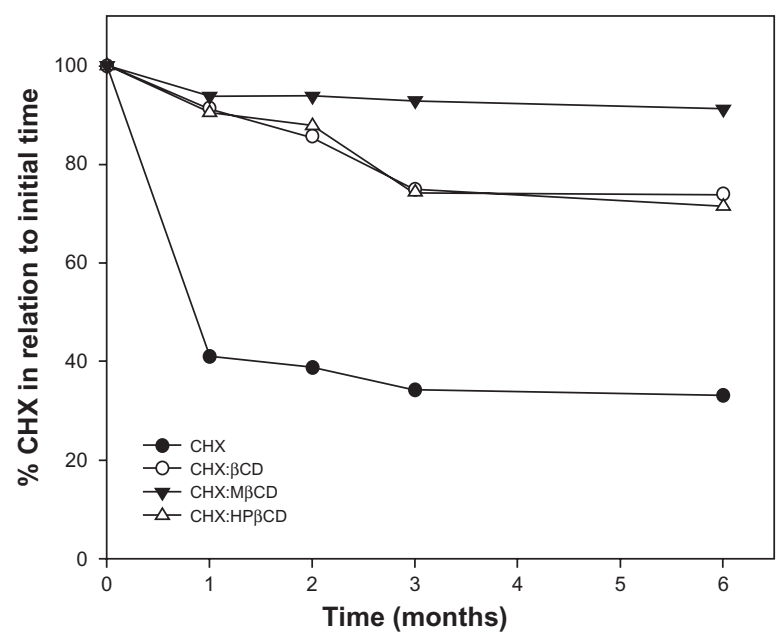

Figure 7 Stability profile of mouth wash formulation containing $\mathrm{CHX}$ not included, and inclusion complexes of $\beta C D, M \beta C D$, and $\mathrm{HP} \beta C D$ stored at $40^{\circ} \mathrm{C} \pm 2{ }^{\circ} \mathrm{C}$ and $75 \% \pm 5 \%$ relative humidity for 6 months.

Abbreviations: $\beta C D, \beta$-cyclodextrin; $C H X$, chlorhexidine; $H P \beta C D$, hydroxypropyl$\beta$-cyclodextrin; $M \beta C D$, methyl- $\beta$-cyclodextrin.
CHX and the inclusion complexes using $0.12 \% \mathrm{w} / \mathrm{v}$ CHX content. These samples were stored in a climatic chamber at $45^{\circ} \mathrm{C} \pm 2{ }^{\circ} \mathrm{C}$ and $75 \% \pm 5 \%$ relative humidity (RH) in order to evaluate the thermal stability. The results of the stability study are presented in Figure 7, and a great increase in the stability of all nanosystems studied can be seen, indicating the potential for the commercial application of these new $\mathrm{CD}$ derivatives.

\section{Conclusion}

XRPD, FTIR, and DSC analysis were used to confirm the proposed nanosystems formation and the suitability of the production methods. However, the nanosystems that showed best antimicrobial effect were $\mathrm{CHX}$ and $\mathrm{CD}$ inclusion complexes and CHX:MMTNa 60\% CEC - 24 hours. Although NYS nanosystems presented no antimicrobial activity with the technique applied here, this does not preclude their use since this method does not represent in-vivo conditions. Moreover, these nanosystem formulations present the following improvements: higher stability for all chlorhexidine inclusion complexes compared with pure chlorhexidine under $40^{\circ} \mathrm{C} \pm 2^{\circ} \mathrm{C}$ and $75 \% \pm 5 \% \mathrm{RH}$ and being a sustained release system, the potential for NYS nanosystems to mask the bitter 
taste, justifying subsequent in-vivo studies. For these reasons, further studies are being carried out to evaluate their application in professional formulations.

\section{Acknowledgments}

This work was supported by FAPERJ, CAPES Edital CAPES Nanobiotecnologia 2008 and CNPq.

\section{Disclosure}

The authors report no conflicts of interest in this work.

\section{References}

1. Skartveit L, Selvig KA, Myklebust S, Tveit AB. Effect of Tif4 Solutions on bacterial-growth in vitro and on tooth surfaces. Acta Odontol Scand. 1990;48(3):169-174.

2. Ates M, Akdeniz BG, Sen BH. The effect of calcium chelating or binding agents on Candida albicans. Oral Surg Oral Med Oral Pathol Oral Radiol Endod. 2005;100(5):626-630.

3. Kolenbrander PE. Oral microbial communities: biofilms, interactions, and genetic systems. Annu Rev Microbiol. 2000;54:413-437.

4. Escribano M, Herrera D, Morante S, Teughels W, Quirynen M, Sanz M. Efficacy of a low-concentration chlorhexidine mouth rinse in noncompliant periodontitis patients attending a supportive periodontal care programme: a randomized clinical trial. J Clin Periodontol. 2010;37(3): 266-275.

5. Winkel EG, Roldán S, Van Winkelhoff AJ, Herrera D, Sanz M. Clinical effects of a new mouth rinse containing chlorhexidine, cetylpyridinium chloride and zinc-lactate on oral halitosis. J Clin Periodontol. 2003; 30(4):300-306.

6. Soares da Silva LF, do Carmo FA, de Almeida Borges VR, et al. Preparation and evaluation of lidocaine hydrochloride in cyclodextrin inclusion complexes for development of stable gel in association with chlorhexidine gluconate for urogenital use. Int J Nanomedicine. 2011;6: $1143-1154$

7. Wang CS, Arnold RR, Trope M, Teixeira FB. Clinical efficiency of $2 \%$ chlorhexidine gel in reducing intracanal bacteria. J Endodont. 2007; 33(11):1283-1289.

8. Loftsson T, Brewster ME. Pharmaceutical applications of cyclodextrin I. Drug solubilization and stabilization. J Pharm Sci. 1996;85(10):1017-1025.

9. Hoppe JE. Treatment of oropharyngeal candidiasis in immunocompetent infants: a randomized multicenter study of miconazole gel vs nystatin suspension. Pediatr Infect Dis J. 1997;16(3):288-293.

10. de Soet JJ, Gruythuysen RJ, Bosch JA, van Amerongen WE. The effect of 6-monthly application of $40 \%$ chlorhexidine varnish on the microflora and dental caries incidence in a population of children in Surinam. Caries Res. 2002;36(6):449-455.

11. Meng N, Zhou NL, Zhang SQ, Shen J. Controlled release and antibacterial activity chlorhexidine acetate (ca) intercalated in montmorillonite. Int J Pharm. 2009;382(1-2):45-49.

12. Ray SS, Yamada K, Okamoto M, Ogami A, Ueda K. New polylactide/ layered silicate nanocomposites. 3. High-performance biodegradable materials. Chem Mater. 2003;15(7):1456-1465.

International Journal of Nanomedicine

\section{Publish your work in this journal}

The International Journal of Nanomedicine is an international, peerreviewed journal focusing on the application of nanotechnology in diagnostics, therapeutics, and drug delivery systems throughout the biomedical field. This journal is indexed on PubMed Central, MedLine, CAS, SciSearch ${ }^{\circledR}$, Current Contents ${ }^{\circledR} /$ Clinical Medicine,
13. Martin Del Valle EM. Cyclodextrins and their uses: a review. Process Biochem. 2004;39:1033-1046.

14. Davis ME, Brewster ME. Cyclodextrin-based pharmaceutics: Past, present and future. Nat Rev Drug Discov. 2004;3(12):1023-1035.

15. Loftsson T, Duchêne D. Cyclodextrins and their pharmaceutical applications. Int J Pharm. 2007;329(1-2):1-11.

16. United States Pharmacopeia. Monograph: Chlorehexidine Gluconate Oral Rinse. 34th ed. Rockville, MD: The United States Pharmacopeial Convention; 2011;II:2297.

17. International Conference on Harmonization (ICH). Q1A(R2). Stability testing of new drug substance and products. US FDA Federal Register, 2003. http://www.ich.org/fileadmin/Public_Web_Site/ICH_Products/ Guidelines/Quality/Q1A_R2/Step4/Q1A_R2_Guideline.pdf. Accessed October 4, 2011.

18. Cortés ME, Sinisterra RD, Avila-Campos MJ, Tortamano N, Rocha RG. The chlorhexidine: $\beta$-cyclodextrin inclusion compound: Preparation, characterization and microbiological evaluation. $J$ Incl Phenom Macrocycl Chem. 2001;40(4):297-302.

19. Figueiras A, Ribeiro L, Vieira MT, Veiga F Preparation and physicochemical characterization of omeprazole: methyl-beta-cyclodextrin inclusion complex in solid state. J Incl Phenom Macrocycl Chem. 2007;57(1):173-177.

20. Wang J, Cao Y, Sun B, Wang C. Characterization of inclusion complex of trans-ferulic acid and hydroxypropyl- $\beta$-cyclodextrin. Food Chem. 2011;124(3):1069-1075.

21. Giordano F, Novak C, Moyano JR. Thermal analysis of cyclodextrins and their inclusion compounds. Thermoch Acta. 2001;380(2):123-151.

22. Yallapu MM, Jaggi M, Chauhan SC. Beta-Cyclodextrin-curcumin selfassembly enhances curcumin delivery in prostate cancer cells. Colloids Surf B Biointerfaces. 2010;79(1):113-125.

23. Zhang J, Cheng X, Liu H, Lu W. Synthesis and properties of poly(vinyl alcohol)/synthetic F-montmorillonite nanocomposites. Chin J Chem. 2009;27(8):1611-1616.

24. Yang D, Yuan P, Zhu JX, He HP. Synthesis and characterization of antibacterial compounds using montmorillonite and chlorhexidine acetate. J Therm Anal Calorim. 2007;89(3):847-852.

25. Joshi GV, Patel HA, Kevadiya BD, Bajaj HC. Montmorillonite intercalated with vitamin B-1 as drug carrier. Appl Clay Sci. 2009;45(4): 248-253.

26. Meng N, Zhou N, Zhang S, Shen J. Synthesis and antimicrobial activities of polymer/montmorillonite-chlorhexidine acetate nanocomposite films. Appl Clay Sci. 2009;42:667-670.

27. He H, Yang D, Yuan P, Shen W, Frost RL. A novel organoclay with antibacterial activity prepared from montmorillonite and Chlorhexidini Acetas. J Colloid Interface Sci. 2006;297(1):235-243.

28. Carrillo-Muñoz AJ, Quindós G, Tur C, et al. In-vitro antifungal activity of liposomal nystatin in comparison with nystatin, amphotericin B cholesteryl sulphate, liposomal amphotericin B, amphotericin B lipid complex, amphotericin B desoxycholate, fluconazole and itraconazole. J Antimicrob Chemother. 1999;44(3):397-401.

29. Rasimick BJ, Nekich M, Hladek MM, Musikant BL, Deutsch AS. Interaction between chlorhexidine digluconate and EDTA. $J$ Endod. 2008;34(12):1521-1523.

30. Basrani BR, Manek S, Sodhi RNS, Fillery E, Manzur A. Interaction between sodium hypochlorite and chlorhexidine gluconate. $J$ Endod. 2007;33(8):966-969.

\section{Dovepress}

Journal Citation Reports/Science Edition, EMBase, Scopus and the Elsevier Bibliographic databases. The manuscript management system is completely online and includes a very quick and fair peer-review system, which is all easy to use. Visit http://www.dovepress.com/ testimonials.php to read real quotes from published authors. 